\title{
Clean Room Spacewalk (Stairs and Walkway)
}

\author{
Engineering Note \#3740.520-EN-200
}

Issued: Jan. 4, 1989

Revised: Jan. 23, 1989

Originator: Al Jaques

Checked: 
D-Zero Engineering Note

3740.520-EN-200

Issued $1 / 4 / 89$

Revised 1/23/89

\section{Clean Room Spacewalk (Stairs and Walkway)}

\section{Al Jaques}

The CC Cryostat was moved to the cleanroom for the installation of modules. Work will continue on the top of the Cryostat with the help of platforms attached to both sides of the Cryostat. It was desired to access this platform from a nearby balcony via a walkway or "spacewalk". The spacewalk was to attach to the substructure of the east fold-down platform and across the balcony to some kind of staircase structure. The final design was a free standing stair frame and a rectangular box platform with handrails which hooks onto the stair frame and the substructure of the platform. A sketch of the cleanroom and spacewalk are included following this report.

Since the spacewalk structure had to be hand assembled once on the balcony, the material chosen was stock 6061-T6 aluminum. This aluminum combines high-strength (35 ksi yield) and light weight. A 1-1/2" aluminum bar across the staircase provides the structure for the walkway platform to hook onto. No-skid pads are placed on the channel stairs and the surface of the walkway platform to assure sure footing. The level of the walkway platform lies approximately $10^{\prime \prime}$ below the surface of the fold-down platform, thus requiring users to step up onto the platform.

The stress calculations and sketches are included at the end of this report. AISC rules were adhered to in designing and constraining the accompanying stresses. 


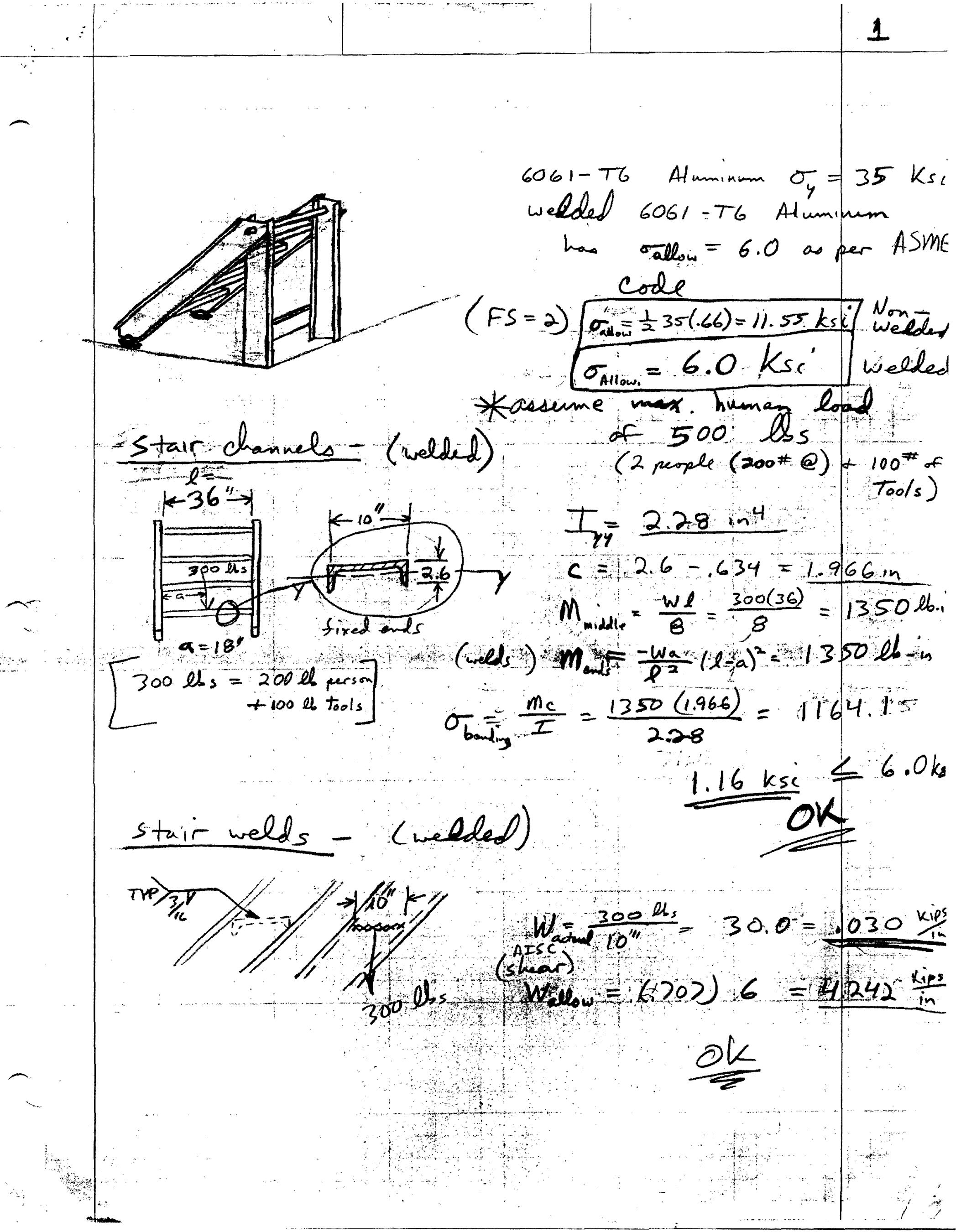




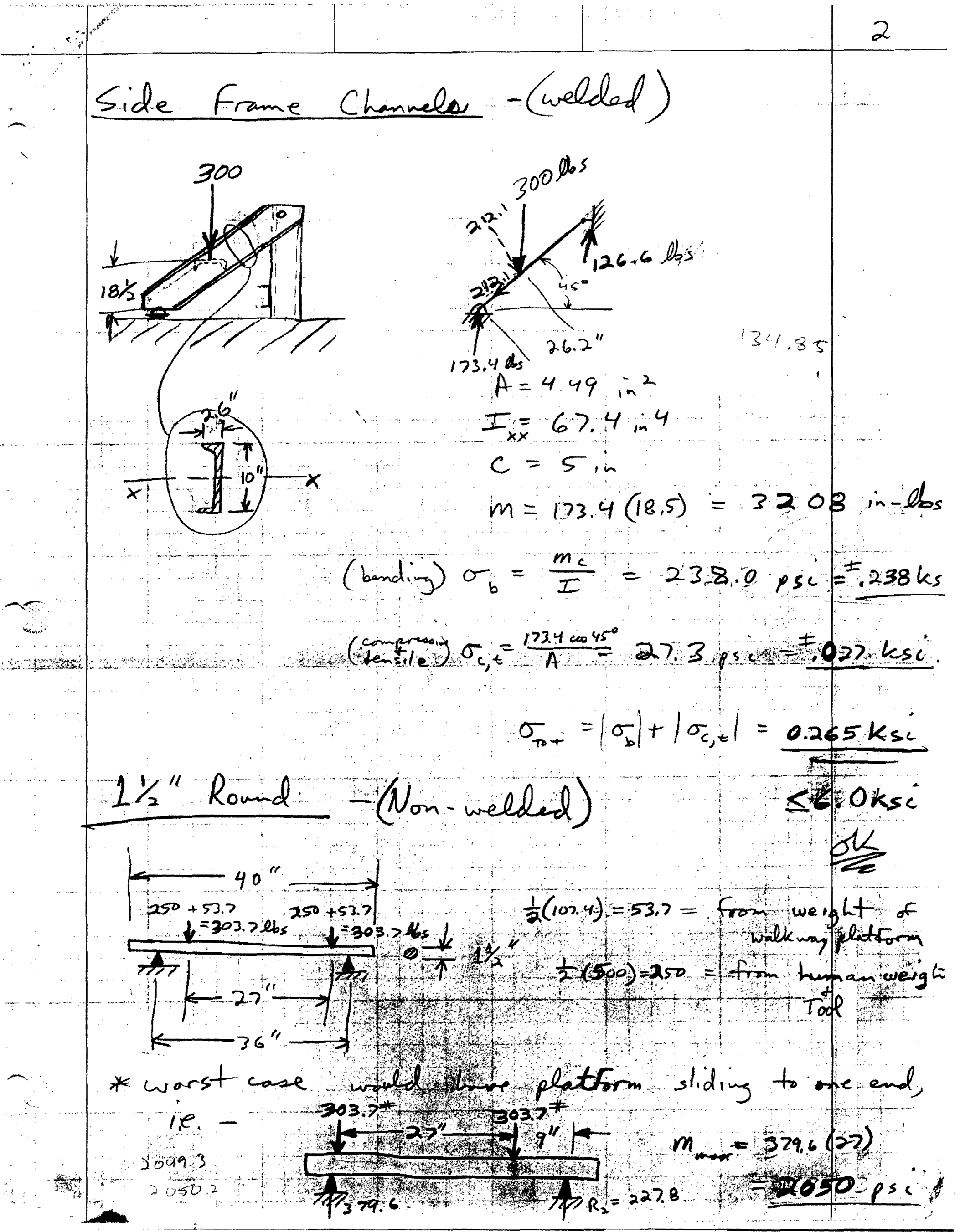




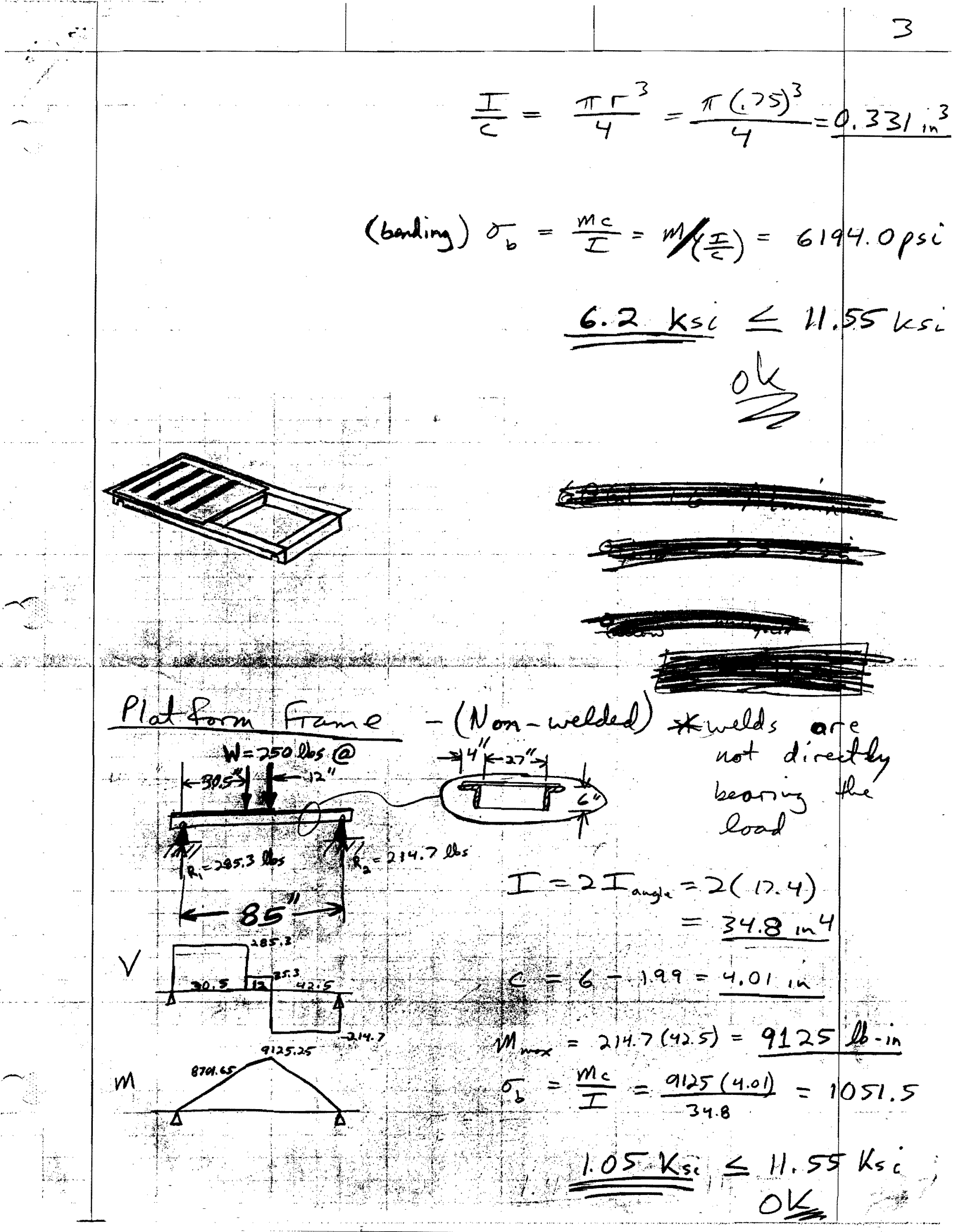




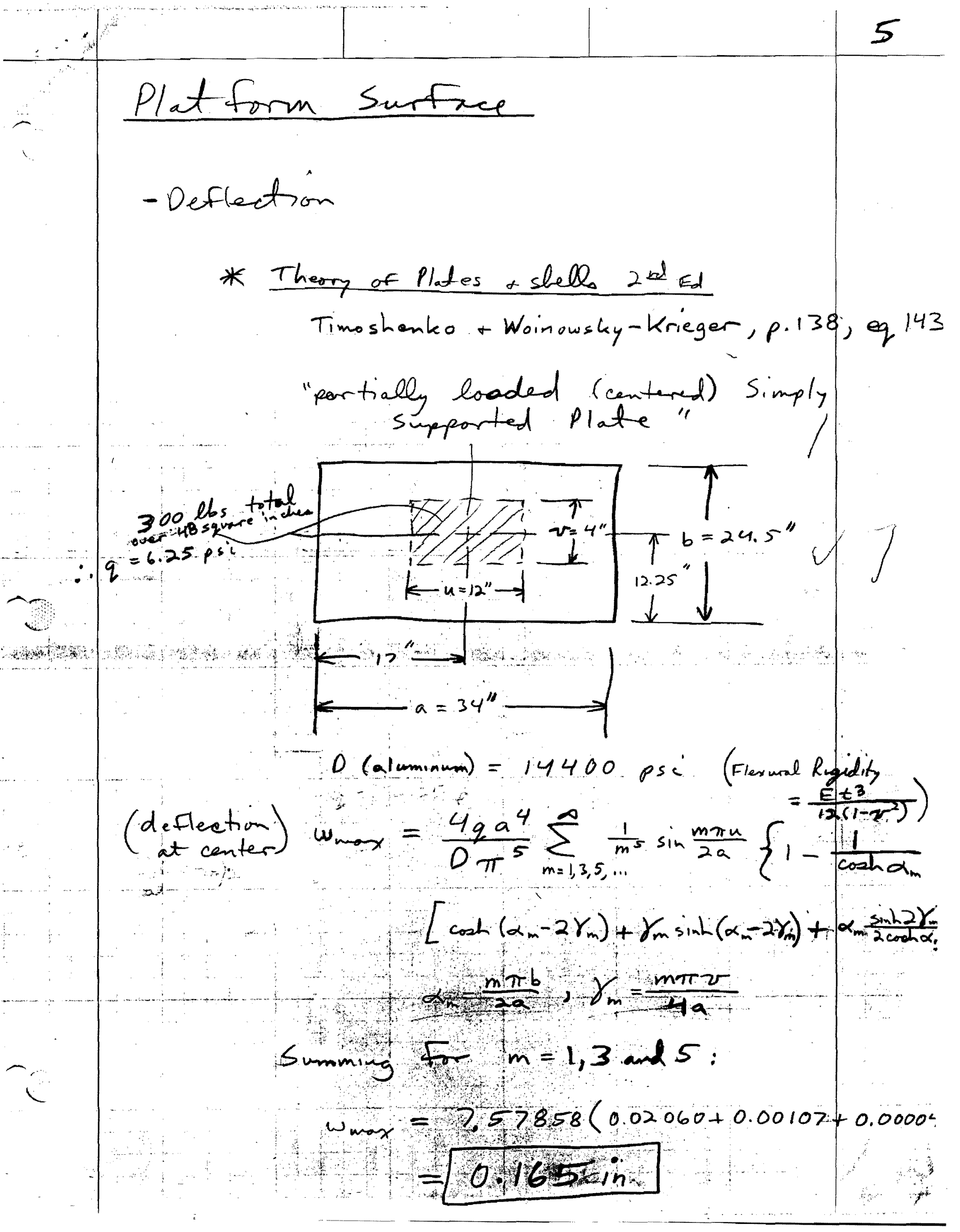


FRAME MAC file: Untitled; Last modified at 1:53:03 PM on Wed, Jan 25, 1989

Above each load are the magnitudes in $\mathrm{lb}, \mathrm{lb} / \mathrm{ft}$, and $\mathrm{lb}-\mathrm{in}$.

Next to each support are reactions in $\mathrm{lb}$ and $\mathrm{lb}$-in.

Positive reactions and deformations are to the right, upwards, and counter-clockwise.

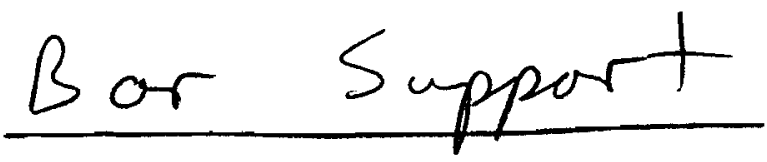

$f X=0.00 \theta+0^{F Y}=3.04 \theta+2$
$f Y=4.66 e+2$

$F Y=3.04 e+2$ 
FRAME MAC file: Untitled; Last modified at 1:53:03 PM on Wed, Jan 25, 1989

Node 1 FReact MReact Elem 1,2 Node 2 FReact

$\mathrm{L}=6.20 \theta+1 \quad 6.80 \theta+10.00 \theta+0$

$6.00 \theta+0 \quad 4.66 \theta+2 \quad L \quad L=6.20 \theta+1 \quad 6.00 \theta+0 \quad 1.69 \theta+2$

MReact

$E=2.900+7$

FL1

$0.00 \theta+0$

$0.00 \theta+0$

$3.04 \theta+2$

$3.04 \theta+2$

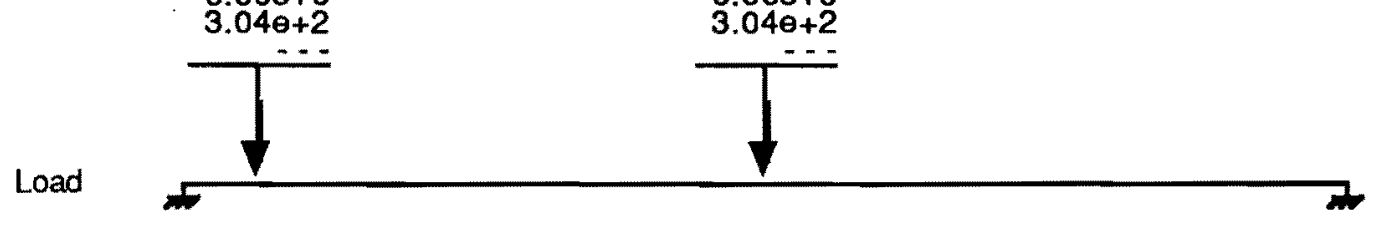

Tension

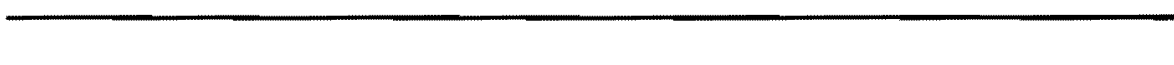

0.00

$F:$ lb

D: $\mathrm{lb} / \mathrm{ft}$

M: lb-in

E: psi

Shea

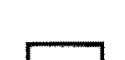

Ib

$0.00 \theta+0$

$4.66 \theta+2$

Ib

$-1.69 \theta+2$

$2.463 \theta+3$

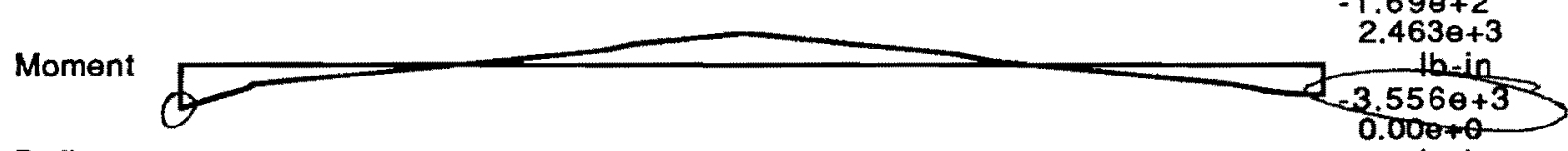

Defl.

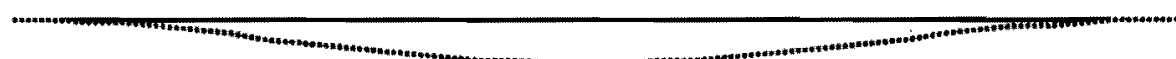

inch

$-2.83 \theta-2$

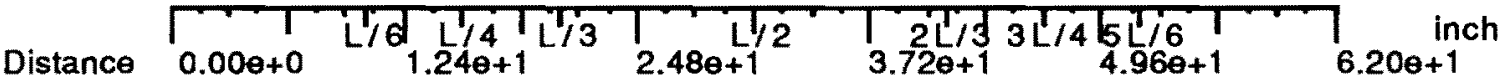


FRAME MAC file: Untitled; Last modified at 9:53:18 AM on Thu, Jan 26, 1989 Displayed on each element is: Max. absolute bending stress in units of psi.

Above each load are the magnitudes in $\mathrm{lb}, \mathrm{lb} / \mathrm{ft}$, and $\mathrm{lb}-\mathrm{ft}$.

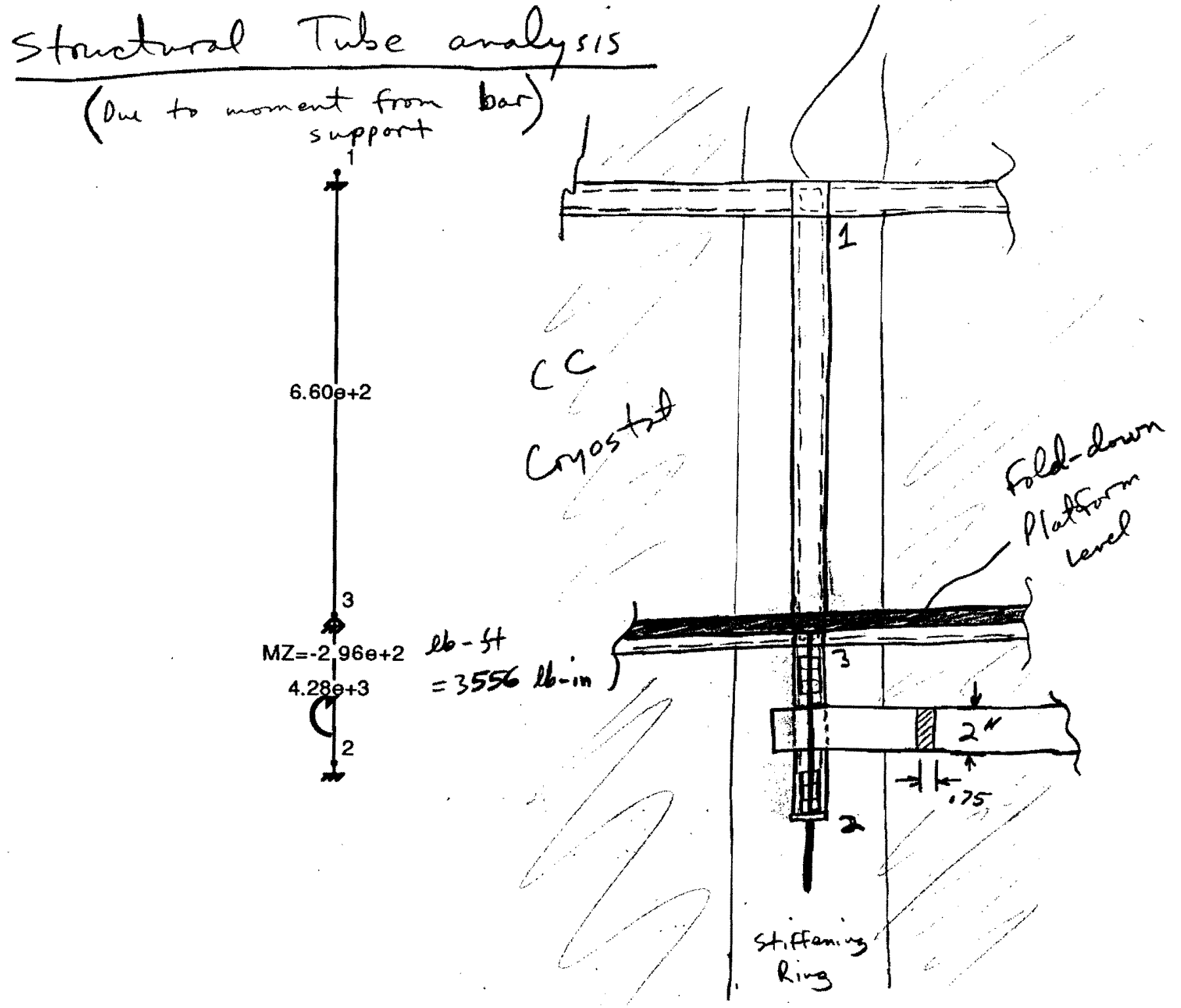




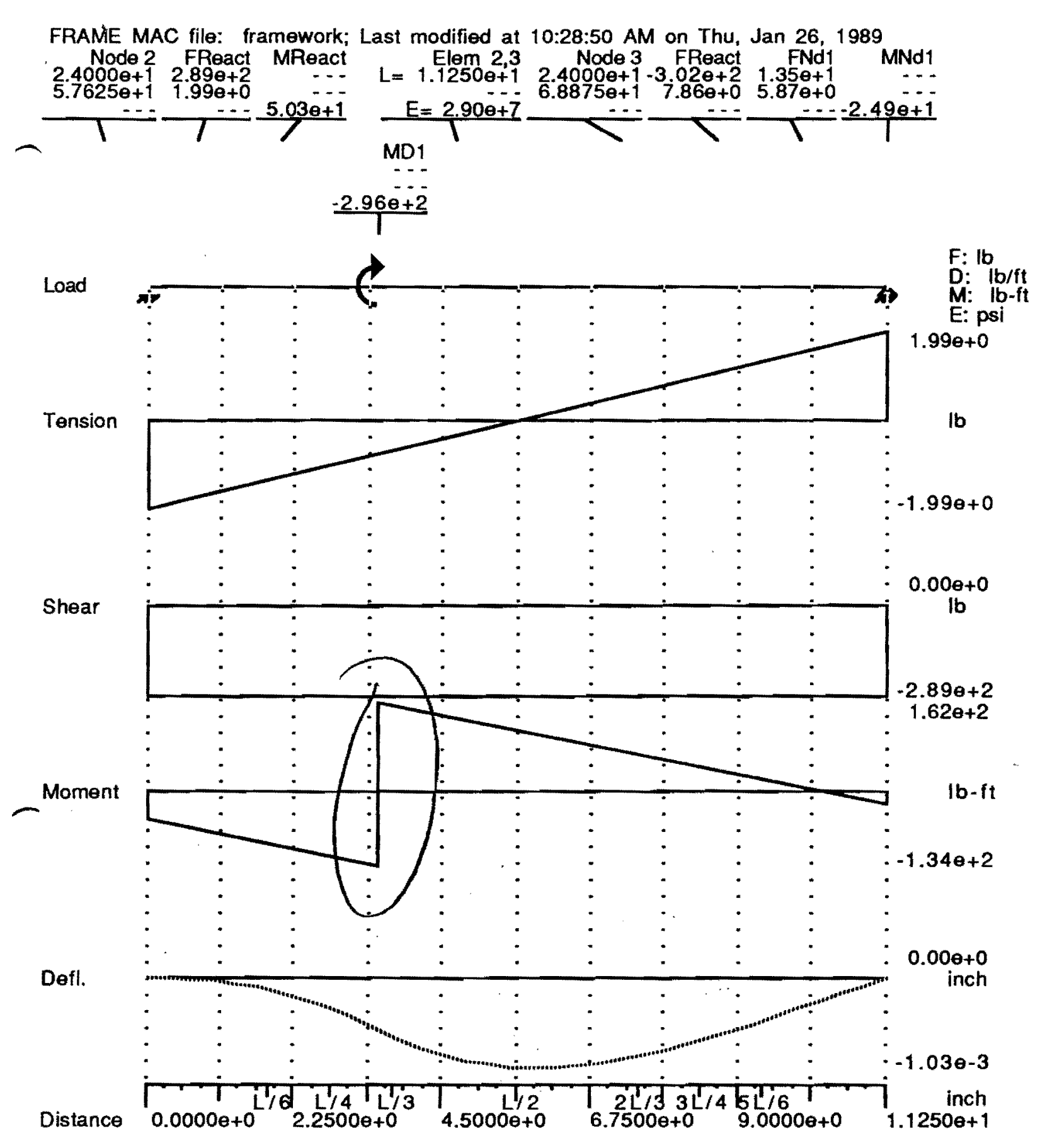

11 


$$
\frac{1}{x}
$$


